\title{
USING THE NEW FIBRE CONTACT ELEMENT METHOD FOR DYNAMIC STRUCTURAL ANALYSIS
}

\author{
João M. C. ESTÊVÃO, Ana S. CARREIRA \\ Department of Civil Engineering, University of Algarve, Campus da Penha, Faro, 8005-139 Portugal
}

Received 18 June 2015; accepted 24 August 2015

\begin{abstract}
In literature, there are many methods proposed for structural analysis based on discrete element formulations, mainly for nonlinear problems. One of these new methods is the Fibre Contact Element Method (FCEM). Many of these methods have been used for structural dynamic analysis problems. However, there are some questions about their precision in capturing the dynamic elastic response of structures when comparing to methods based on continuous models, like the well known Finite Element Method (FEM). For this reason, the results obtained with FCEM were extensively compared with FEM results and with laboratorial tests, to better understand the performance of this new method in capturing the elastic dynamic response of structures. Results indicate that this kind of discrete methods are able to determine the vibration modes of a structure with equal or better precision level than the obtained with FEM. FCEM was also used to capture the dynamic response of a reinforced concrete frame with infill walls, as a way to show the method capabilities in reproducing the dynamic behaviour of structures that have an almost continuous mass distribution.
\end{abstract}

Keywords: discrete methods, FCEM, dynamic analysis, FEM, laboratory tests, infill walls.

\section{Introduction}

Over the last years, several methods involving discrete models have been proposed for modelling very complex dynamic systems as an alternative to the more traditional methods, which are based on continuous models.

The Finite Element Method (FEM) is one of the most popular method that uses continuous structural models, with a good accuracy when comparing with in situ dynamic measures (Paeglite et al. 2015). FEM has also been used for seismic nonlinear analysis of masonry structures which is a very heterogeneous material (Milani et al. 2011).

Methods based on discrete element formulations like the Discrete (or Distinct) Element Method (DEM) are a group of numerical methods in which the models consist in a set of bodies interacting with each other by contact laws. Cohesive links between bodies can be a set of normal springs, normal and transverse springs or beam elements (Jebahi et al. 2014).

Unlike FEM, which uses continuous models, discrete models are discontinuous systems, and there is no attempt to obtain a continuous stress distribution throughout the discrete elements contact surface. However, DEM may have significant advantages in failure analysis of masonry structures (Lemos 2007).

FEM and DEM can be divided in two major groups, depending on the structure scale: macro-models and micro-models. Macro-models are numerical models that incorporate the behaviour of large parts of the structure. On the other hand, micro-models allow reproducing the influence of very small details on the overall structural behaviour (Estêvão, Oliveira 2015).

Corresponding author:

J. M. C. Estêvão E-mail: jestevao@ualg.pt 
Jebahi et al. (2014) divided micro-models in four groups, depending on the scale of analysis: the nanoscopic scale $\left(\sim 10^{-9} \mathrm{~m}\right)$, the microscopic scale $\left(\sim 10^{-6}\right.$ $\mathrm{m})$, the mesoscopic scale $\left(\sim 10^{-4} \mathrm{~m}\right)$, and the macroscopic scale $\left(\sim 10^{-2} \mathrm{~m}\right)$.

Normally, discrete bodies are defined as polygonal block elements connected with springs or are defined as smaller granular (particles) elements (Lemos 2007). Block elements can be modelled as rigid elements (Meguro, Tagel-Din 2001; Casolo, Milani 2010; Dimitri et al. 2011; McInerney, DeJong 2014) or as deformable elements (Jin et al. 2011; Caliò et al. 2012; Rafiee, Vinches 2013; Ulrich et al. 2015). Particle elements can be spherical or can present a more complex shape (Huang et al. 2015). Spherical particles have been used for structural analysis of continuous structures, using spring links (Liu, K., Liu, W. 2006; Wu, Zhang 2015). In granular flow problems a damping link between particles is also considered (Huang et al. 2015; Grima, Wypych 2011; Mechtcherine et al. 2014). Polyhedral particles linked with springs are also an option for use it in DEM (Seyedi Hosseininia 2012; Norouzi et al. 2013). Particle elements can also be linked with beam elements (Schlangen, Garboczi 1996; D'addetta et al. 2002; André et al. 2012).

DEM have been widely used for structural dynamics problems. However, it seems obvious that the smaller the body in the structural model, the higher the computer time consuming for solving a dynamic problem. Additionally, results may also be influenced by the level of the structure discretization, which have influence in the computational effort necessary to solve the problem (Meguro, Tagel-Din 2001). This can be a problem for computer implementation of this kind of methods for solving practical problems involving very large structures, because the amount of memory needed could be prohibitive (Schlangen, Garboczi 1997), even for the actual personal computers.

Unlike continuous approaches like FEM, the main challenge for DEM is to properly reproduce the behaviour of continuous structures, namely in the elastic domain. To overcome this problem, many hybrid methods have been proposed that combines DEM and FEM characteristics, mainly using discrete models to only capture material fracture (Azevedo, Lemos 2006; Smoljanović et al. 2013; Carmona et al. 2014; Tatone, Grasselli 2015).

In this context, a new method was developed based on a discrete element formulation, which was named Fibre Contact Element Method (FCEM), and implemented in a computer program named FIBERBLOC2D (Estêvão 2012). The FCEM was mainly developed for structural nonlinear analysis and results were compared with good agreement to analytical solutions and experimental results (Estêvão, Oliveira 2015; Estêvão, Carvalho 2015). This new type of DEM method can also be adapted for solving structural dynamic analysis problems, as presented in this paper. However, some doubts about the capacity of FCEM in capturing the dynamic behaviour of continuous structures still remain, which must be overcomed.

In this paper, FCEM results obtained with different levels of structural discretization were compared with values that were obtained experimentally in laboratory. FCEM results were also compared with analytical results and with numerical results obtained with FEM.

After the FCEM validation, FIBERBLOC2D was used for the dynamic analysis of a concrete frame with infill masonry walls to illustrate FCEM potential, and results were compared with FEM results obtained with a more traditional model (normally used in structural design) to observe the differences between them.

\section{Fibre contact element method (FCEM)}

FCEM is a new approach for structural analysis, developed and implemented in the software FIBERBLOC2D (Estêvão 2012). This method was inspired in several structural analysis existent methods, like fibre models and previous DEM formulations, but with a new implementation strategy and structural analysis approach, trying to overcome some computational limitations that seem to exist in many DEM methods.

In this new method, structural systems are divided in small rectangular deformable block elements, which are in contact with each other. Each contact element is divided in several small fibres, with rectangular cross sections. Fibres belonging to neighbouring block elements are in contact with each other through a contact point. Fibres are modelled as inflexible elements of length $L_{N}$ (half of the block dimension), but having normal $\left(k_{N}\right)$ and transverse stiffness $\left(k_{V}\right)$. Block element fibres stiffness are concentrated at two springs, which are connected to contact points (hinges) (Estêvão 2012; Estêvão, Oliveira 2015), as presented Figure 1 . The fibre stiffness is defined as:

$$
k_{N}=\frac{E \cdot A}{L_{N}}
$$




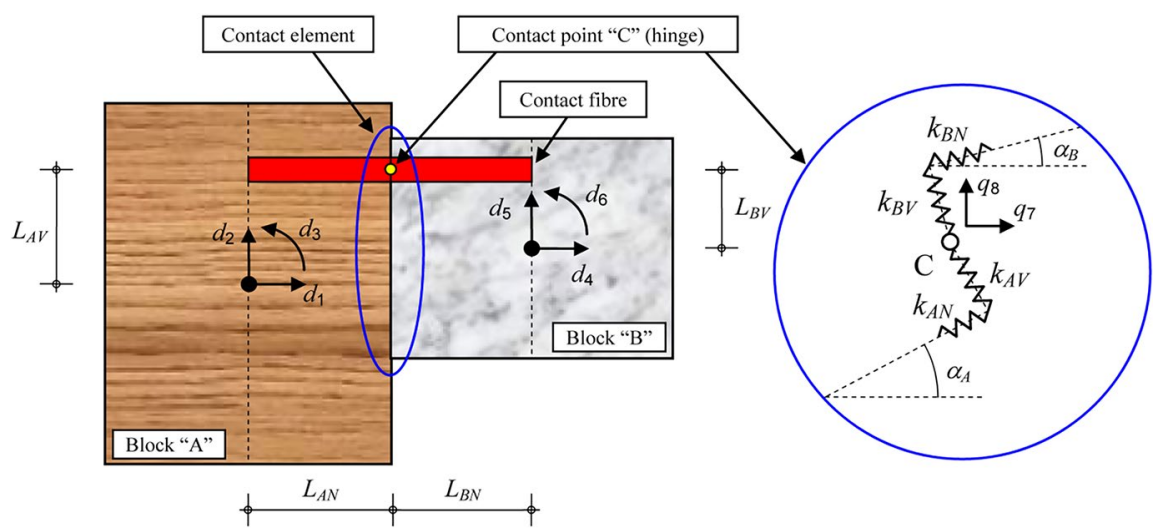

Fig. 1. Schematic representation of two neighbouring block elements and a fibre contact point as used in the FCEM

$$
k_{V}=\frac{G \cdot A}{L_{N}} \cdot \frac{5}{6},
$$

where $E$ is the modulus of elasticity, $G$ is the shear modulus, $A$ is the fibre area (Fig. 1).

The global stiffness of the structure is associated to the "rigid body" degrees of freedom of each block element $\left(d_{1}\right.$ to $\left.d_{3}\right)$, and can be obtained by summing the contribution of each fibre element. The elemental stiffness matrix for each fibre element, associated to local directions $\left(q_{1}\right.$ to $\left.q_{8}\right)$, can be obtained as

$$
\left[k_{q}\right]=\left[\begin{array}{ll}
{\left[k_{q A B}\right]} & {\left[k_{q A B C}\right]} \\
{\left[k_{q C A B}\right]} & {\left[k_{q C C}\right]}
\end{array}\right],
$$

where sub-matrices $\left[k_{q A B}\right]$ and $\left[k_{q C A B}\right]$ are associated to displacements $q_{1}$ to $q_{6}$ (block element displacements in local directions), and sub-matrices $\left[k_{q A B C}\right]$ and $\left[k_{q C C}\right]$ are associated to contact point (C) displacements $q_{7}$ and $q_{8}$ (Estêvão 2012; Estêvão, Oliveira 2015). Variables $q_{7}$ and $q_{8}$ are very important, because they capture the contour block element deformation.

A new system of linear equations can be obtained:

$$
\begin{gathered}
{\left[k_{q}\right] \cdot\left\{\begin{array}{l}
\left\{q_{A}\right\} \\
\left\{q_{B}\right\} \\
\left\{q_{C}\right\}
\end{array}\right\}=\left\{\begin{array}{l}
\left\{F_{q_{A}}\right\} \\
\left\{F_{q_{B}}\right\} \\
\left\{F_{q C}\right\}
\end{array}\right\} ;} \\
\left\{q_{A}\right\}=\left\{\begin{array}{lll}
q_{1} & q_{2} & q_{3}
\end{array}\right\}^{T} ; \\
\left\{q_{B}\right\}=\left\{\begin{array}{lll}
q_{4} & q_{5} & q_{6}
\end{array}\right\}^{T} ; \\
\left\{q_{C}\right\}=\left\{\begin{array}{ll}
q_{7} & q_{8}
\end{array}\right\}^{T},
\end{gathered}
$$

in which $\left\{F_{q A}\right\},\left\{F_{q B}\right\}$, and $\left\{F_{q C}\right\}$ are force vectors ap- plied to block elements A and B, and to contact point $\mathrm{C}$, respectively.

Solving Eq. (4) in order to $\left\{q_{C}\right\}$, the following system of equations is obtained:

$$
\left\{\begin{array}{l}
{\left[k_{q A B}\right] \cdot\left\{\begin{array}{l}
\left\{q_{A}\right\} \\
\left\{q_{B}\right\}
\end{array}\right\}+\left[k_{q A B C}\right] \cdot\left\{q_{C}\right\}=\left\{\begin{array}{l}
\left\{F_{q A}\right\} \\
\left\{F_{q B}\right\}
\end{array}\right\},} \\
{\left[k_{q C A B}\right] \cdot\left\{\begin{array}{l}
\left\{q_{A}\right\} \\
\left\{q_{B}\right\}
\end{array}\right\}+\left[k_{q C C}\right] \cdot\left\{q_{C}\right\}=\left\{F_{q C}\right\}}
\end{array}\right.
$$

which leads to

$$
\begin{aligned}
& \left\{q_{C}\right\}=\left[k_{q C C}\right]^{-1} \cdot\left(\left\{F_{q C}\right\}-\left[k_{q C A B}\right] \cdot\left\{\begin{array}{l}
\left\{q_{A}\right\} \\
\left\{q_{B}\right\}
\end{array}\right\} ;\right. \\
& {\left[k_{q e}\right] \cdot\left\{\begin{array}{l}
\left\{q_{A}\right\} \\
\left\{q_{B}\right\}
\end{array}\right\}=\left\{F_{q e}\right\}=\left\{\begin{array}{l}
\left\{F_{q e A}\right\} \\
\left\{F_{q e B}\right\}
\end{array}\right\} ;} \\
& {\left[k_{q e}\right]=\left[k_{q A B}\right]-\left[k_{q A B C}\right] \cdot\left[k_{q C C}\right]^{-1} \cdot\left[k_{q C A B}\right] ;} \\
& {\left[k_{q e}\right]=\left[\begin{array}{l}
{\left[k_{q e A A}\right]\left[k_{q e A B}\right]} \\
{\left[k_{q e B A}\right]\left[k_{q e B B}\right]}
\end{array}\right]}
\end{aligned}
$$

in which $\left[k_{q e}\right]$ is the new elemental stiffness matrix, only associated with block element displacements $\left(q_{1}\right.$ to $q_{6}$ ). The elimination of $q_{7}$ and $q_{8}$ variables is mainly to minimize the global stiffness matrix dimension, which reduces the computer processing time and the amount of computer memory required.

Using the following coordinates transformation

$$
\begin{aligned}
& \left\{q_{A}\right\}=\left[T_{A}\right] \cdot\left\{d_{A}\right\} ; \\
& \left\{q_{B}\right\}=\left[T_{B}\right] \cdot\left\{d_{B}\right\} ; \\
& \left\{d_{A}\right\}=\left\{\begin{array}{lll}
d_{1} & d_{2} & d_{3}
\end{array}\right\}^{T} ; \\
& \left\{d_{B}\right\}=\left\{\begin{array}{lll}
d_{4} & d_{5} & d_{6}
\end{array}\right\}^{T},
\end{aligned}
$$


where $\left[T_{A}\right]$ and $\left[T_{B}\right]$ are the following transformation matrices:

$$
\begin{aligned}
& {\left[T_{A}\right]=\left[\begin{array}{ccc}
\cos \alpha_{A} & \sin \alpha_{A} & 0 \\
-\sin \alpha_{A} & \cos \alpha_{A} & 0 \\
0 & 0 & 1
\end{array}\right] ;} \\
& {\left[T_{B}\right]=\left[\begin{array}{ccc}
\cos \alpha_{B} & \sin \alpha_{B} & 0 \\
-\sin \alpha_{B} & \cos \alpha_{B} & 0 \\
0 & 0 & 1
\end{array}\right] .}
\end{aligned}
$$

The elemental stiffness matrix in global directions $\left(d_{1}\right.$ to $\left.d_{6}\right)$ can be determined solving the following system of equations:

$$
\begin{aligned}
& \left\{\begin{array}{l}
{\left[k_{q e A A}\right] \cdot\left\{q_{A}\right\}+\left[k_{q e A B}\right] \cdot\left\{q_{B}\right\}=\left\{F_{q e A}\right\}} \\
{\left[k_{q e B A}\right] \cdot\left\{q_{A}\right\}+\left[k_{q e B B}\right] \cdot\left\{q_{B}\right\}=\left\{F_{q e B}\right\}}
\end{array} ;\right. \\
& \left\{\begin{array}{l}
\left\{\left[k_{q e A A}\right] \cdot\left[T_{A}\right] \cdot\left\{d_{A}\right\}+\left[k_{q e A B}\right] \cdot\left[T_{B}\right] \cdot\left\{d_{B}\right\}=\left\{F_{q e A}\right\}\right. \\
{\left[k_{q e B A}\right] \cdot\left[T_{A}\right] \cdot\left\{d_{A}\right\}+\left[k_{q e B B}\right] \cdot\left[T_{B}\right] \cdot\left\{d_{B}\right\}=\left\{F_{q e B}\right\}}
\end{array} .\right.
\end{aligned}
$$

Multiplying the first row of Eq. (20) by $\left[T_{A}\right]^{\mathrm{T}}$ and the second row by $\left[T_{B}\right]^{\mathrm{T}}$, the new elemental fibre stiffness matrix in global directions $\left[k_{d}\right]$ is obtained as follows:

$$
\left[k_{d}\right]=\left[\begin{array}{l}
{\left[T_{A}\right]^{T} \cdot\left[k_{q e A A}\right] \cdot\left[T_{A}\right]\left[T_{A}\right]^{T} \cdot\left[k_{q e A B}\right] \cdot\left[T_{B}\right]} \\
{\left[T_{B}\right]^{T} \cdot\left[k_{q e B A}\right] \cdot\left[T_{A}\right]\left[T_{B}\right]^{T} \cdot\left[k_{q e B B}\right] \cdot\left[T_{B}\right]}
\end{array}\right] .
$$

The stiffness matrix of each contact element between neighbouring blocks is the sum of the contribution of all $\left(N_{m}\right)$ contact fibre element stiffness matrices

$$
\left[k_{e}\right]=\sum_{i=1}^{N_{m}}\left[k_{d}\right]_{(i)} .
$$

The stiffness matrix $[k]$ of the global structure results from the assembly of all elemental contact stiffness matrices $\left[k_{e}\right]$. The adopted elemental mass matrix of each block element incorporates the rotational inertia, and can be determined as

$$
\left[m_{e}\right]=\rho_{i} \cdot b_{i} \cdot L_{x i} \cdot L_{y i} \cdot\left[\begin{array}{ccc}
1 & 0 & 0 \\
0 & 1 & 0 \\
0 & 0 & \frac{1}{12}\left(L_{x i}^{2}+L_{y i}^{2}\right)
\end{array}\right]
$$

where $\rho_{i}$ is the block $i$ mass per unit volume, $b_{i}$ is the block width, $L_{x i}$ and $L_{y i}$ are the in-plane block dimensions.

The global mass matrix $[m]$ results from the assembly of all elemental mass matrices $\left[m_{e}\right]$.
Once the stiffness and mass global matrices are obtained, the natural frequencies and vibration mode shape configurations are obtained through an inverse iteration scheme (Clough, Penzien 1993), which was implemented in FIBERBLOC2D.

\section{Laboratorial tests}

To test the reliability of FCEM results for dynamic analysis of continuous structures in the elastic domain, a simply supported concrete beam was constructed and tested in the laboratories of the Civil Engineering Department (DEC-ISE) of the University of Algarve, Portugal. In opposition to other studies, in which a special care was taken to isolate the tested concrete beam (Ndambi et al. 2005), in this work the laboratorial tests were carried out with a more complex support conditions, in order to evaluate the capacity of each studied model to reproduce the dynamic behaviour of real structures. For this reason, and also to enable static tests, the concrete beam (with low resistance) was placed on a steel frame structure.

The reinforced concrete beam specimen (Fig. 2) was simply supported on steel rollers $(2.30 \mathrm{~m}$ between supports) and had a rectangular cross section $(0.10 \times$ $0.12 \mathrm{~m}$ ), with four longitudinal $8 \mathrm{~mm}$ steel bars and steel hoops of $6 \mathrm{~mm}$ in diameter at $20 \mathrm{~cm}$ spacing. The static and dynamic laboratorial tests performed on the beam are described in detail in the following sections.

\subsection{Static tests}

Two tests were carried out to assess the elastic characteristics of the concrete beam (Fig. 3), namely to obtain the tangent Young's modulus $(E)$ of the used concrete.

The first laboratorial static test was carried out in a concrete cylindrical specimen $(15 \mathrm{~cm}$ in diameter and $30 \mathrm{~cm}$ height) using a standard elastic modulus testing apparatus (Fig. 3a), which was constituted by two rings fixed to the concrete test specimen. The concrete deformation was measured by a linear displacement transducer connected between the rings, when the specimen was subjected to a compression force. A load cell was used to obtain the applied compression force.

The second static test was carried out directly in the simply supported concrete beam. A concentrated force was applied in the middle of the beam, and the vertical displacement versus applied static force was continuously recorded in the middle span section (Fig. 3b). 


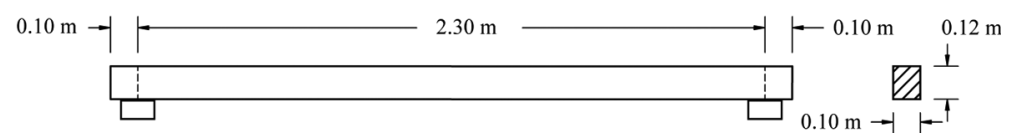

Fig. 2. Dimensions of the tested reinforced concrete beam
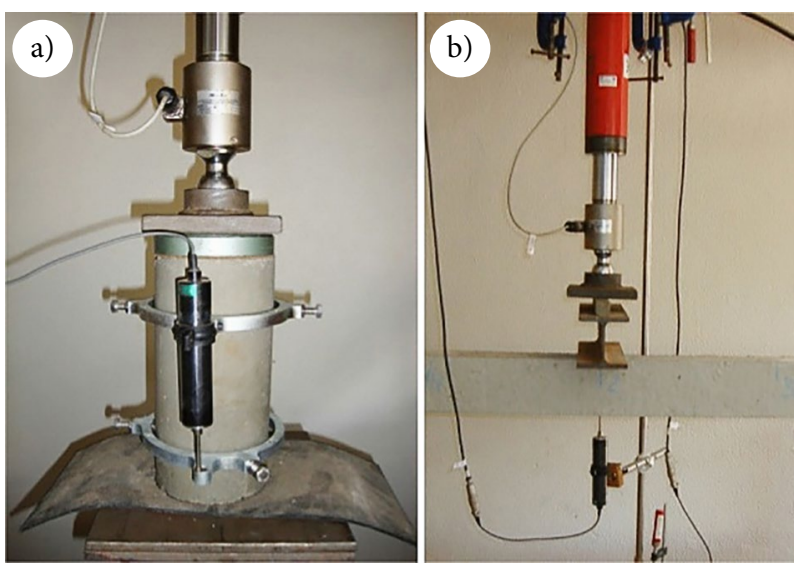

Fig. 3. Adopted procedure for the Young's modulus determination: a) cylindrical specimen test; b) simply supported beam test

\subsection{Dynamic tests}

The simply supported reinforced concrete beam was subjected to a vibration induced by the impact of a hammer, which was similar to a white noise. Vibrations in the vertical direction were registered by a dual channel real time frequency analyzer in the frequency range of $10 \mathrm{~Hz}$ to $300 \mathrm{~Hz}$. Several tests were carried out using two accelerometers placed on the upper part of the beam, but in different locations (Fig. 4).

In the vibration tests, the action applied by the hammer was not measured, and so a modal identification method was adopted, only based in the recorded structural response. The Basic Frequency Domain method (BFD) was used to obtain the natural frequencies of vibration of the structure, which is based on the

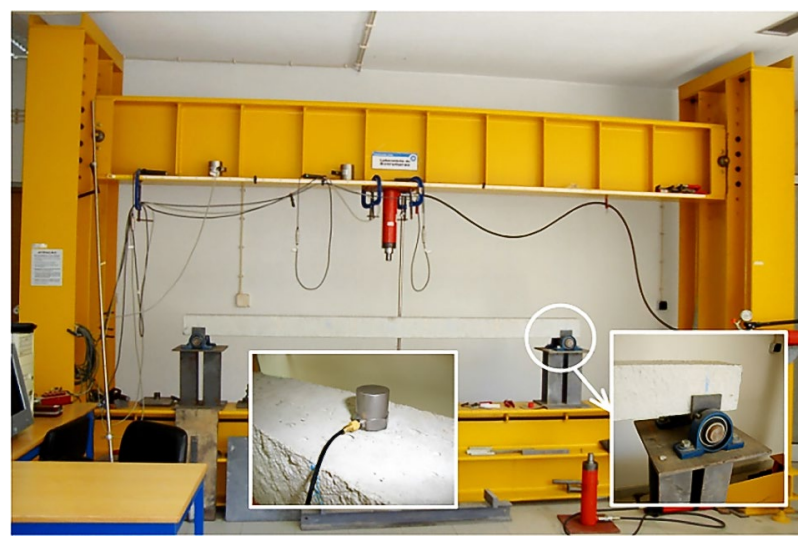

Fig. 4. Experimental dynamic setup test fact that response frequency functions attain extreme values near the natural frequencies of vibration (Bendat, Piersol 1993; 2010). In this way, natural frequencies were determined by observing the peaks of the Average Normalized Power Spectral Density (ANPSD) graphical chart, which results from the power spectral density functions obtained from the experimental dynamic tests (Felber 1993).

From the recorded acceleration time histories obtained during the dynamic tests, and using some basic notions of digital processing and spectral analysis (Bendat, Piersol 1993; 2010), it was possible to obtain the Power Spectral Density (PSD) functions after using a Fast Fourier Transform (FFT) algorithm.

An isolated analysis would be insufficient to identify all the resonance frequencies of the structure, because the uniaxial accelerometers could be placed in a node with a null vertical displacement in a given mode shape. Thus, a total of 18 different responses were registered, nine of them corresponding to tests that were carried out using different dynamic force application points.

Different temporal series were collected from the vibration tests, each one corresponding to the average of 64 independent samples of 2048 number of sampling points and to a sampling time interval of $2 \mathrm{~s}$, for each other. A sampling frequency of $1024 \mathrm{~Hz}$ was considered, which gives a Nyquist critical frequency of $512 \mathrm{~Hz}$ and a frequency interval of $0.5 \mathrm{~Hz}$ (Shannon 1949a; Shannon 1949b). A low pass filter with a cut off frequency of $400 \mathrm{~Hz}$ was applied to eliminate errors due to signal discretization (aliasing errors). A Hanning window was also applied to attenuate the errors related to the finite nature of the temporal series (leakage errors).

\section{Analytical and numerical analysis}

Static and dynamic analysis of a simply supported reinforced concrete beam (RC) and dynamic analysis of a steel frame structure were used to compare the results of different analytical and numerical methods to better evaluate the FCEM precision. All dimensions of the structural elements considered in the analysis were obtained from in situ measurements. Results 
were compared between each other and with the experimental data.

First, the concrete beam was studied as an isolated dynamic system, and then the concrete beam was studied in combination with the supporting steel frame system.

Previous studies showed that FCEM results precision is dependent on the number of block elements and fibres used in the structural model (Estêvão 2012; Estêvão, Oliveira 2015). This knowledge has influenced the structure discretization adopted in the following structural analysis cases.

\subsection{RC beam structure}

Five structural analyses were carried out for the RC beam structure, which are described as follows:

- Analysis no. 1 - This analysis was carried out using the theoretical analytical expressions deducted for a simply supported beam.

- Analysis no. 2 and 3 - FEM analysis with two different structure discretizations. For the beam second analysis, a FEM model with beam elements was adopted. A total of 110 elements (100 elements between supports) were considered, with 111 nodes (333 degrees-of-freedom) where the mass was concentrated. To better capture the support conditions, a vertical concrete element was introduced in the model, connecting the horizontal concrete beam elements to the steel plate at the support (Fig. 5 - model no. 2). A low stiffness horizontal spring was considered at each support trying to model the friction between the concrete beam and the steel plates of the supports. The value of the spring stiffness $(34 \mathrm{kN} / \mathrm{m})$ was determined so that the maximum beam deflection obtained for a static load of $1 \mathrm{kN}$ was equal to the experimental value. Structural analysis no. 3 was also carried out with FEM. In this analysis, five rows of rectangular shell finite elements were used (Fig. 5 - model no. 3), with a total of 540 elements and with 654 nodes were mass was concentrated (1962 degrees-of-freedom). The number of elements of each row was equal to the number of horizontal beam elements of the structural analysis no. 2, to better compare the results. Support conditions were also the same as for the analysis no. 2 .

- Analysis no. 4 and 5 - These analyses were carried out with FCEM. Two different structure discretizations were used. To better compare the differences between FCEM and FEM results, the number of the adopted blocks for the beam discretization in the structural analysis no. 4 was equal to the number of beam elements adopted in analysis no. 2 (Fig. 5 model no. 4). A steel block was considered in each support, which is also connected to a horizontal spring, trying to reproduce the real support conditions of the RC beam. The model no. 4 includes 110 block elements (330 degrees-of-freedom). Each block element was divided into 50 fibres at the contact elements. This means that for a single block connected to a neighbour one, 106 degrees-of-freedom (3 at each block centres and more 100 at contact points) were used to create the matrix of each contact element (which is the sum of the 50 fibre contact element matrices), but only 6 were used in the global stiffness matrix. In structural analysis no. 5 (Fig. 5 model no. 5), the number of concrete block elements was the same as for analysis no. 3, but with two more steel blocks at supports, so the total number of block elements was 542 (1626 degrees-of-freedom). Each block element was divided into 50 fibres at contact elements, as for the analysis no. 4.

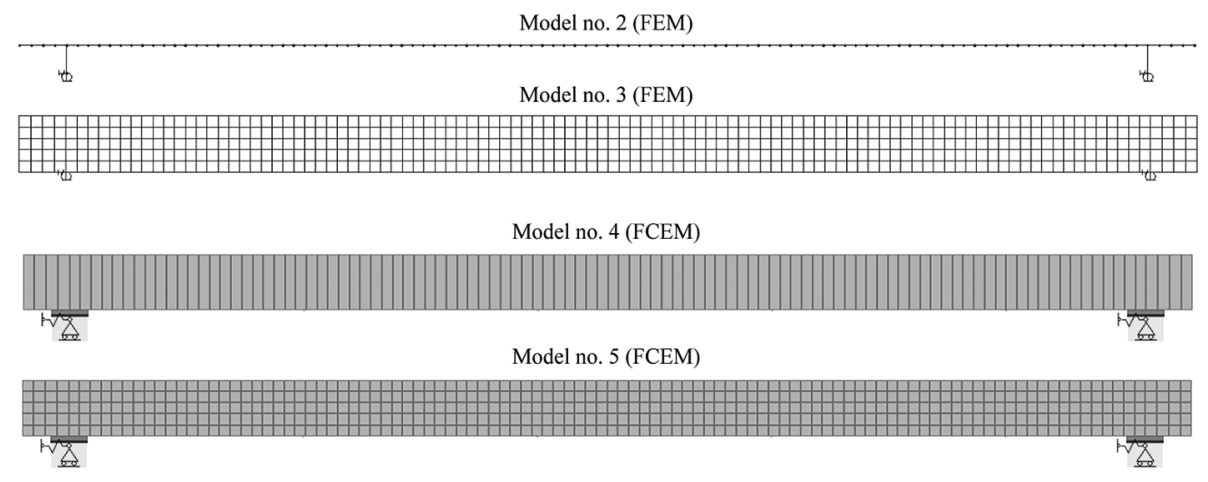

Fig. 5. RC beam models adopted for the structural analysis carried out with FEM and FCEM methods 


\subsection{Steel frame structure}

Three dynamic structural analyses were carried out for the steel structure using FEM and FCEM methods. The adopted models are presented in Figure 6.

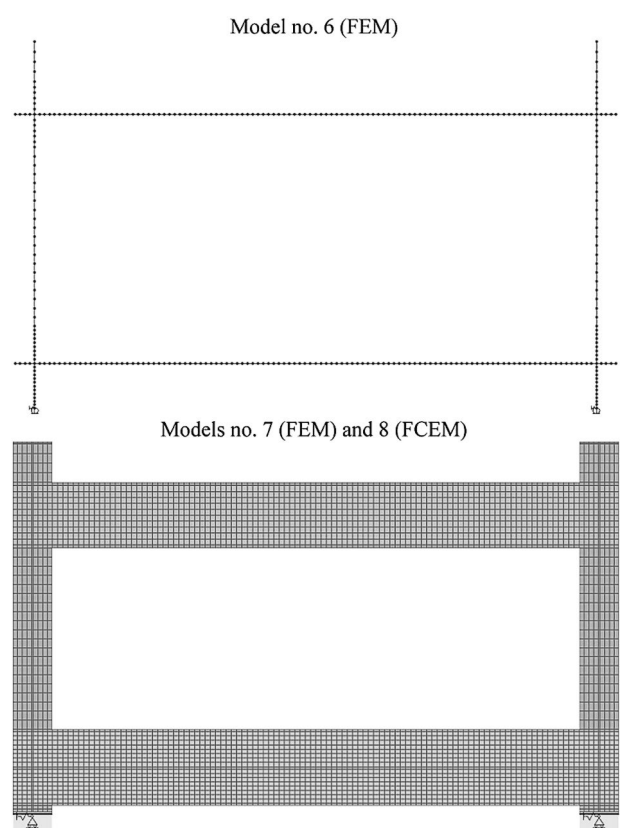

Fig. 6. Steel frame models adopted for the dynamic analysis carried out with FEM and FCEM methods

The numerical dynamic analysis carried out for the steel frame structure, were:

- Analysis no. 6 and 7 - These analyses were carried out using FEM. In analysis no. 6 , the frame structure was divided in 346 beam/column elements, with a total number of 346 nodes. This means that a total of 1038 degrees-of-freedom were used in the model (Fig. 6 - model no. 6). In analysis no. 7, a regular mesh of 4164 rectangular shell finite elements with four nodes was adopted (Fig. 6 - model no. 7). The total number of nodes was 4469 , which leads to a total of 13407 degrees-of-freedom.

- Analysis no. 8 - A regular block element distribution was also adopted in the FCEM model no. 8, which was similar to the element mesh adopted in FEM frame model no. 7 (4164 block elements). Each contact element was divided in 10 fibres. A total of 12492 degrees-of-freedom were used in this model.

\section{3. $\mathrm{RC}$ frame structure with infill walls}

To illustrate the potential of FCEM, three dynamic analyses were carried out for a $\mathrm{RC}$ frame (C30/37) with masonry infill walls (with openings) as presented in Figure 7:
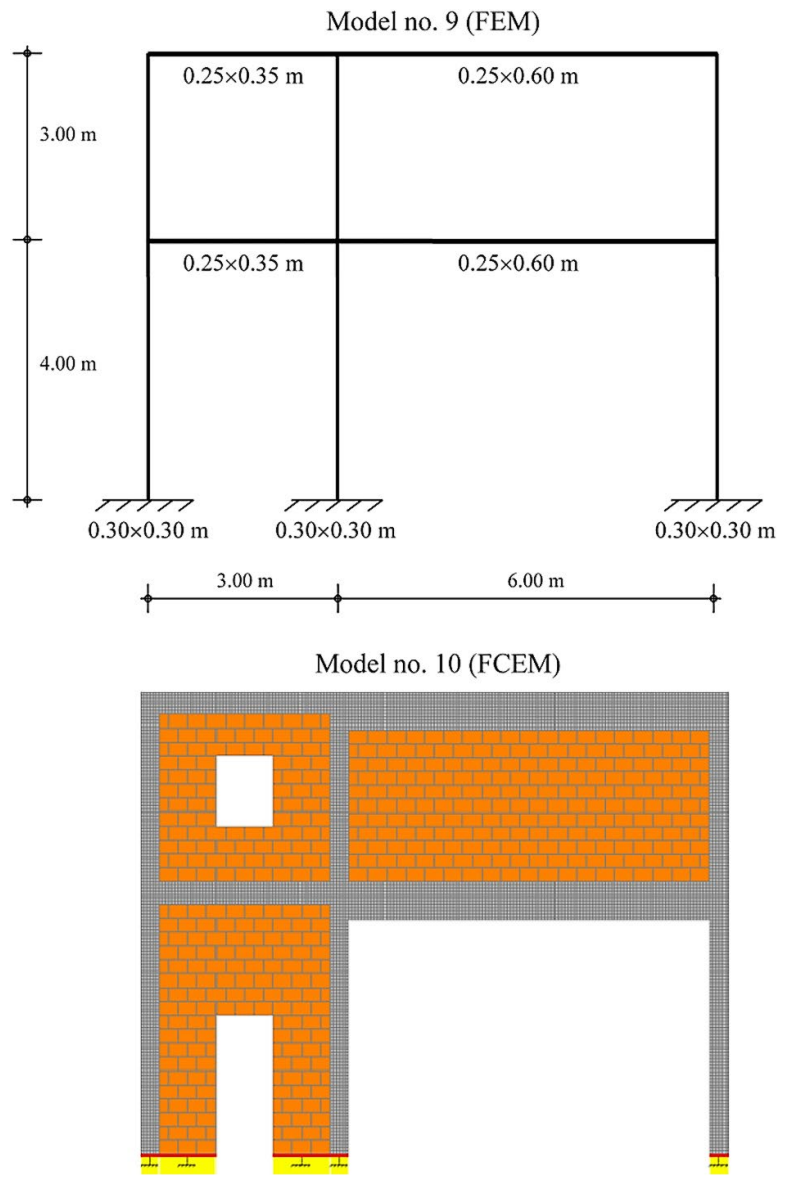

Fig. 7. RC frame with infill walls models adopted for the dynamic analysis carried out with FEM and FCEM methods

- Analysis no. 9 - This was a more traditional dynamic analysis of a RC frame structure without infill walls, only considering 9 nodes (where all the mass was concentrated) and 10 beam/column elements, using FEM (Fig. 7 - model no. 9). In this analysis, masonry infill walls were considered for mass calculation only.

- Analysis no. 10 - This analysis was carried out with FCEM and with a more detailed model of the structure (Fig. 7 - model no. 10), also including the infill masonry walls in the model (6581 RC and masonry block elements). The adopted characteristics for the masonry walls (considered to be made of ceramic hollow bricks and cement mortar) were obtained from laboratorial tests (Braga, Estevao 2007). The adopted wall width was $0.22 \mathrm{~m}$, with elastic modulus equal to $1.4 \mathrm{GPa}$, and material weight equal to $9.1 \mathrm{kN} / \mathrm{m}^{3}$. It is important to notice that model no. 10 does not present neighbour blocks with the same size, which illustrate the potential of the new FCEM. 
- Analysis no. 11 - This analysis was also carried out without masonry infill walls but using FCEM instead of FEM and with the mass distributed along the beams and columns as in model no. 10 (Fig. 7) but without the infill walls, and with only $6120 \mathrm{RC}$ block elements.

Besides the mass of the structure and the mass of the infill walls, an additional mass of $3.65 \mathrm{ton} / \mathrm{m}$ (from a reinforced concrete floor) was also considered to be applied to the beam elements.

\section{Laboratorial test results}

A tangent Young's modulus $(E)$ value of $9507 \mathrm{MPa}$ was obtained in the first static test that was carried out on the cylindrical concrete specimen (Fig. 3a).

During the second static test, a maximum displacement of $1.865 \mathrm{~mm}$ was registered in the section of middle span of the concrete beam, when a force of $1 \mathrm{kN}$ was applied in the same section (Fig. 3b).

The measured mean density value of the concrete ( $\rho$ ) was $2357 \mathrm{~kg} / \mathrm{m}^{3}$.

It is very important to identify the vibration modes from the obtained peaks in the function of spectral density. Since the tested concrete beam was fitted on a steel frame structure (Fig. 4), it enabled us to identify in the vibration tests, not only the natural frequencies of the RC beam, but also the natural frequencies of the steel frame structure, namely those related to the vibration shape modes that involves vertical displacements of the RC beam supports. For this reason, it is important to correlate the obtained experimental results with the analytical and numerical results.
Figure 8 shows the ANPSD graphical chart, resulting from the responses obtained from the experimental vibration tests.

\section{Analytical and numerical structural analysis results}

A total of 16 structural analyses were carried out in this study (5 static analyses and 11 dynamic analyses), in which 10 were related to the simply supported RC structure (2 analytical solutions and 8 numerical, obtained with FEM and FCEM methods, being 5 static and 5 dynamic), 3 were related to the steel frame structure and 3 for the RC frame with infill walls (only numerical dynamic solutions, using FEM and FCEM methods). The FEM results were obtained with the program SAP2000 (CSI 2014) and the FCEM results were obtained with program FIBERBLOC2D (Estêvão 2012). The results are presented and discussed in the following sections, and they are summarized in Tables 1 to 4 .

\subsection{RC beam results}

All the concrete beam results were obtained with a Poisson coefficient value equal to 0.2 , and with the obtained experimental values of $E(9507 \mathrm{MPa})$ and $\rho$ $\left(2357 \mathrm{~kg} / \mathrm{m}^{3}\right)$.

\section{- Analytical beam solutions}

The analytical static solution for the maximum deflection $\left(\delta_{\max }\right)$ of a simply supported reinforced concrete beam subject to a concentrated force $(F)$ at middle span can be obtain with the following expression:

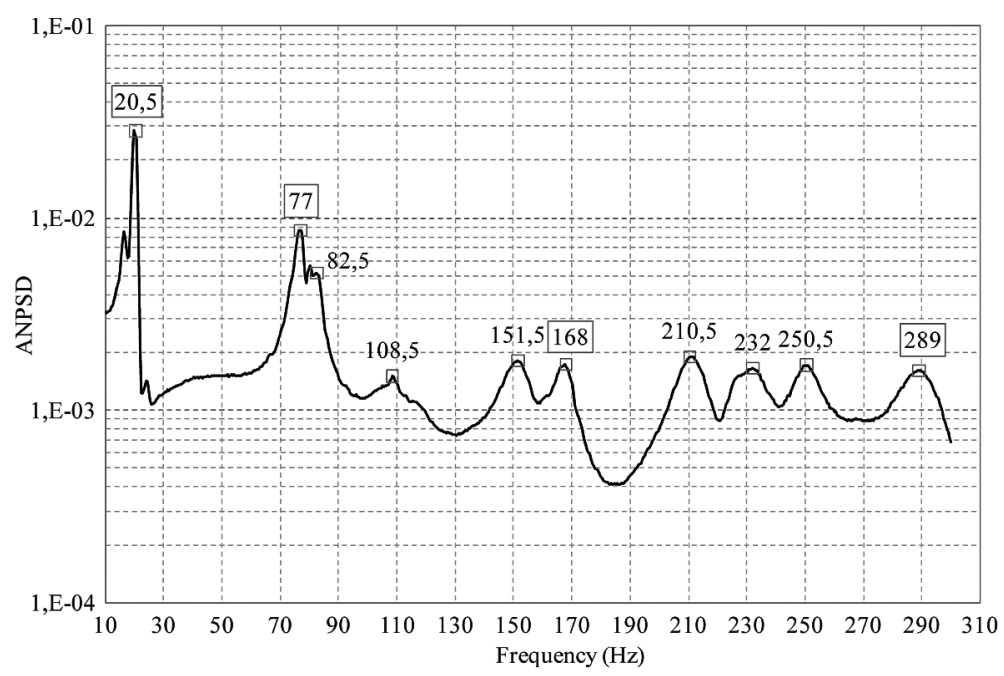

Fig. 8. Averaged normalized power spectral density (ANPSD) 


$$
\delta_{\max }=\frac{F \cdot L^{3}}{48 \cdot E \cdot I},
$$

where $F$ is the force value, $L$ is the beam span value ( $2.30 \mathrm{~m}$ for the studied concrete beam), $E$ is the modulus of elasticity of the material (concrete), and $I$ is the beam cross-section moment of inertia. A value of $1.852 \mathrm{~mm}$ was obtained from Eq. (24). This value is lower than the experimental value, probably because Eq. (24) does not account for the beam shear deformation.

The mathematical procedure to evaluate the behaviour of a continuous dynamic structural system involves differential equations. The simplest mathematical formulation assumes Bernoulli-Euler hypothesis, and is given by

$$
\frac{\partial^{2}}{\partial x^{2}}\left[E I_{(x)} \frac{\partial^{2} v_{(x, t)}}{\partial x^{2}}\right]+m_{(x)} \frac{\partial^{2} v_{(x, t)}}{\partial x^{2}}=p_{(x, t)},
$$

where $E I_{(x)}$ is the flexural stiffness, which is equal to the product between the elastic modulus $(E)$ and the moment of inertia $(I), m_{(x)}$ is the mass per unit length, $p_{(x, t)}$ is an arbitrary load, and $v_{(x, t)}$ is the transverse displacement response (Clough, Penzien 1993).

The solution of Eq. (25) must satisfy the prescribed boundary conditions, and it is difficult to solve for complex practical problems. However, some solutions can be found in the literature for simple case problems, such as for a simply supported beam (Clough, Penzien 1993).

Being $E I$ and mass $(m)$ by unit length constant along the beam, and satisfying the prescribed boundary conditions at $x=0$ and at $x=L$ (which is $2.30 \mathrm{~m}$, as presented in Figure 2), the following expressions are obtained

$$
\begin{gathered}
f_{i}=\frac{\pi \cdot i^{2}}{2} \sqrt{\frac{E \cdot I}{m \cdot L^{4}}} \\
\phi_{i(x)}=\sin \left(\frac{\pi \cdot i \cdot x}{L}\right),
\end{gathered}
$$

where $f_{i}(\mathrm{~Hz})$ is the natural frequency of the vibration mode number $i$, and $\phi_{i(\mathrm{x})}$ is the corresponding mode shape configuration.

The first four natural frequencies obtained with Eq. (26), and the corresponding vibration shape modes obtained with Eq. (27) are shown in Figure 9.

Observing the graphical ANPSD peaks amplitude of the experimental tests and comparing with the obtained analytical solutions, it seems that the corresponding first four modes of the concrete beam are the ones which are closer to the frequencies of $20.5 \mathrm{~Hz}$, $77 \mathrm{~Hz}, 168 \mathrm{~Hz}$ and $289 \mathrm{~Hz}$ (Fig. 8). For this reason, in the following analysis, only the results of the first four modes are presented.

\section{- FEM beam solutions}

Static maximum displacement result of the analysis no. 2 was equal to the experimental value, because the horizontal springs stiffness values were calibrated for so.

Shape vibration of the first four modes obtained for the dynamic analysis no. 2 are presented in Figure 10 , and are similar to the ones obtained in dynamic analysis no. 1 (Fig. 9).

Natural frequencies obtained for the dynamic analysis no. 2 are higher than the corresponding experimental values, with a difference varying between $+0.8 \%$ and $+14.4 \%$. The error seems to increase as the mode order number increases (Table 2).

Model no. 3 seems to be stiffer, because the maximum obtained displacement was lower than the experimental value $(-0.2 \%)$. However, dynamic analysis no. 3 results presented lower errors (Table 2) when comparing to the analysis no. 2 results, but presented the same mode shape configurations.

It should be noticed that all the rigid body vibration modes resulting from the existence of the horizontal springs placed at concrete beam supports were ignored.

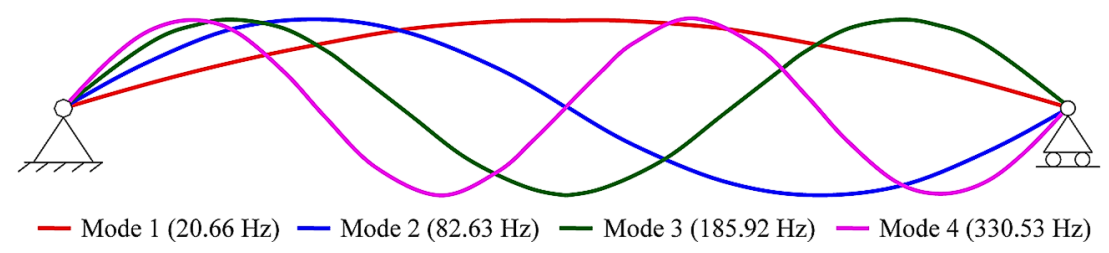

Fig. 9. Natural frequencies and vibration shape mode results of analysis no. 1 (analytical), for the first four beam vibration modes 


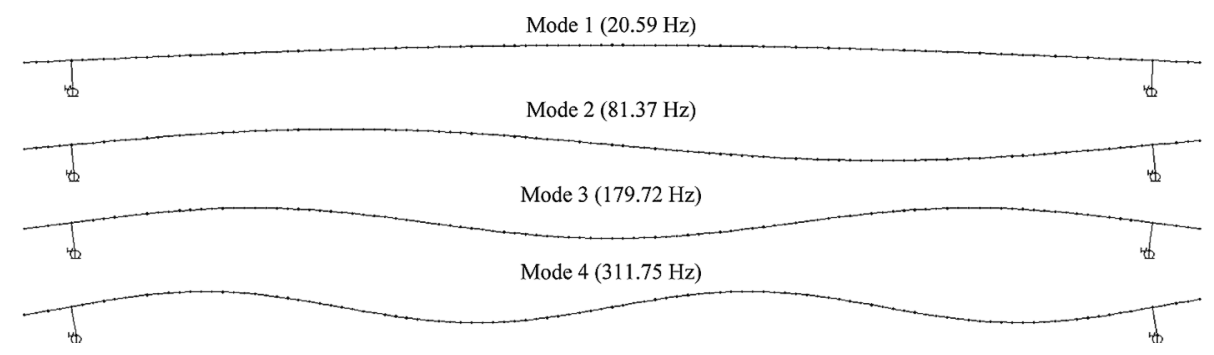

Fig. 10. Natural frequencies and vibration shape mode results of the analysis no. 2 (FEM), for the first four beam vibration modes

\section{- FCEM beam solutions}

Static analysis no. 4 presented almost the same results as for the static analysis no. 2 (with FEM). However, dynamic analysis with FCEM seems to present lower errors (between $+0.3 \%$ and $+6.1 \%$ ), when comparing with the experimental obtained values. The obtained maximum error value is the same as for the model no. 3 (FEM), in spite that model no. 4 (FCEM) has much less degrees-of-freedom. The obtained mode shape configurations with the dynamic analysis no. 4 were identical to the obtained in the previous dynamic analysis, so they are not presented.

Static analysis no. 5 results presented the maximum static error $(+0.9 \%)$. It seems that model no. 5 is less stiff than the others (Table 1). However, the dynamic analysis no. 5 presented the results (Table 2) with the lower mean errors (between $-0.05 \%$ and $+3.6 \%$ ). It is also interesting to notice that errors of the dynamic analysis no. 5 do not increase as the mode order number increases. These differences to FEM results can be related to the way how the supports are modelled, which are more close to the reality, or can be the result of a FCEM better performance, which is a doubt that can not be scientifically clarified yet. The obtained mode shape configurations (Fig. 11) are similar to the ones obtained for the dynamic analysis no. 1 to 4 (Figs 9 and 10). In the dynamic analysis no. 4 and 5 results, the rigid body vibration modes were also ignored due to the existence of the supporting horizontal springs.

\subsection{Steel frame structure results}

For all the three analysis (no. 6, 7 and 8) it was assumed that the steel weight was equal to $78 \mathrm{kN} / \mathrm{m}^{3}$ and that $\mathrm{E}=200 \mathrm{GPa}$. The concrete beam mass was concentrated in the two points where the beam supports were placed. Results are presented in Table 3.

\section{- FEM steel frame solutions}

No correspondence between the natural frequency of the analysis no. 6 first mode results and a peak value of the ANPSD chart was obtained. This is

Table 1. Static $\delta_{\max }(\mathrm{mm})$ results due to a concentrated force of $1 \mathrm{kN}$, obtained with different methods for the studied concrete beam problem, and the corresponding error percentage to the obtained experimental value

\begin{tabular}{|c|c|c|c|c|c|}
\hline $\begin{array}{c}\text { Experimental } \\
\text { obtained value }\end{array}$ & $\begin{array}{c}\text { Analysis no. 1 } \\
\text { (analytical) }\end{array}$ & $\begin{array}{c}\text { Analysis no. 2 } \\
\text { (FEM) }\end{array}$ & $\begin{array}{c}\text { Analysis no. 3 } \\
\text { (FEM) }\end{array}$ & $\begin{array}{c}\text { Analysis no. } 4 \\
\text { (FCEM) }\end{array}$ & $\begin{array}{c}\text { Analysis no. 5 } \\
\text { (FCEM) }\end{array}$ \\
\hline 1.865 & $\begin{array}{c}1.852 \\
(-0.7 \%)\end{array}$ & $\begin{array}{c}1.865 \\
(0 \%)\end{array}$ & $\begin{array}{c}1.861 \\
(-0.2 \%)\end{array}$ & $\begin{array}{c}1.865 \\
(0 \%)\end{array}$ & $\begin{array}{c}1.882 \\
(+0.9 \%)\end{array}$ \\
\hline
\end{tabular}

Table 2. Natural frequency values $(\mathrm{Hz})$ obtained with different methods for the studied concrete beam problem, and the corresponding error percentage to the obtained experimental value

\begin{tabular}{|c|c|c|c|c|c|c|}
\hline $\begin{array}{c}\text { Vibration } \\
\text { mode number }\end{array}$ & $\begin{array}{c}\text { Experimental } \\
\text { obtained value }\end{array}$ & $\begin{array}{c}\text { Analysis no. 1 } \\
\text { (analytical) }\end{array}$ & $\begin{array}{c}\text { Analysis no. 2 } \\
(\text { FEM })\end{array}$ & $\begin{array}{c}\text { Analysis no. 3 } \\
(\text { FEM })\end{array}$ & $\begin{array}{c}\text { Analysis no. 4 } \\
(\text { FCEM })\end{array}$ & $\begin{array}{c}\text { Analysis no. 5 } \\
(\text { FCEM })\end{array}$ \\
\hline 1 & 20.5 & $\begin{array}{c}20.66 \\
(+0.8 \%)\end{array}$ & $\begin{array}{c}20.59 \\
(+0.4 \%)\end{array}$ & $\begin{array}{c}20.56 \\
(+0.3 \%)\end{array}$ & $\begin{array}{c}20.57 \\
(+0.3 \%)\end{array}$ & $\begin{array}{c}20.49 \\
(-0.05 \%)\end{array}$ \\
\hline 2 & 77 & $\begin{array}{c}82.63 \\
(+7.3 \%)\end{array}$ & $\begin{array}{c}81.37 \\
(+5.7 \%)\end{array}$ & $\begin{array}{c}80.99 \\
(+5.2 \%)\end{array}$ & $\begin{array}{c}80.01 \\
(+3.9 \%)\end{array}$ & $\begin{array}{c}79.80 \\
(+3.6 \%)\end{array}$ \\
\hline 3 & 168 & $\begin{array}{c}185.92 \\
(+10.7 \%)\end{array}$ & $\begin{array}{c}179.72 \\
(+7.0 \%)\end{array}$ & $\begin{array}{c}177.92 \\
(+5.9 \%)\end{array}$ & $\begin{array}{c}177.95 \\
(+5.9 \%)\end{array}$ & $\begin{array}{c}172.45 \\
(+2.6 \%)\end{array}$ \\
\hline 4 & 289 & $\begin{array}{c}330.53 \\
(+14.4 \%)\end{array}$ & $\begin{array}{c}311.75 \\
(+7.9 \%)\end{array}$ & $\begin{array}{c}306.71 \\
(+6.1 \%)\end{array}$ & $\begin{array}{c}306.67 \\
(+6.1 \%)\end{array}$ & $\begin{array}{c}291.45 \\
(+0.8 \%)\end{array}$ \\
\hline
\end{tabular}




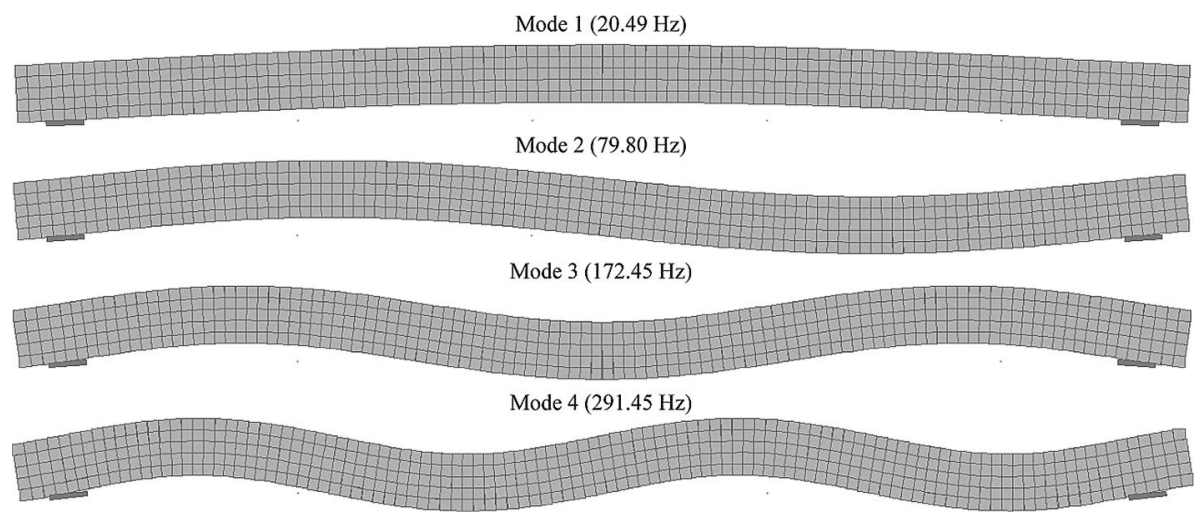

Fig. 11. Natural frequencies and vibration shape mode results of the analysis no. 5 (FCEM), for the first four beam vibration modes

Table 3. Natural frequency values $(\mathrm{Hz})$ obtained with different methods for the studied steel frame structure problem, and the corresponding error percentage to the obtained experimental value

\begin{tabular}{|c|c|c|c|c|}
\hline $\begin{array}{l}\text { Vibration } \\
\text { mode number }\end{array}$ & $\begin{array}{l}\text { Experimental } \\
\text { obtained value }\end{array}$ & $\begin{array}{c}\text { Analysis no. } 6 \\
\text { (FEM) }\end{array}$ & $\begin{array}{c}\text { Analysis no. } 7 \\
\text { (FEM) }\end{array}$ & $\begin{array}{c}\text { Analysis no. } 8 \\
\text { (FCEM) }\end{array}$ \\
\hline 1 & --- & 66.2 & 63.1 & 56.8 \\
\hline 2 & 82.5 & $\begin{array}{c}99.1 \\
(+20.1 \%)\end{array}$ & $\begin{array}{c}89.4 \\
(+8.4 \%)\end{array}$ & $\begin{array}{c}81.8 \\
(-0.8 \%)\end{array}$ \\
\hline 3 & 108.5 & $\begin{array}{c}107.0 \\
(-1.4 \%)\end{array}$ & $\begin{array}{c}109.0 \\
(+0.5 \%)\end{array}$ & $\begin{array}{c}94.1 \\
(-13.3 \%)\end{array}$ \\
\hline 4 & 210.5 & $\begin{array}{c}251.6 \\
(+19.5 \%)\end{array}$ & $\begin{array}{c}244.0 \\
(+15.9 \%)\end{array}$ & $\begin{array}{c}212.0 \\
(+0.7 \%)\end{array}$ \\
\hline 5 & 232 & $\begin{array}{c}255.1 \\
(+10.0 \%)\end{array}$ & $\begin{array}{c}274.1 \\
(+18.1 \%)\end{array}$ & $\begin{array}{c}229.3 \\
(-1.2 \%)\end{array}$ \\
\hline 6 & 250.5 & $\begin{array}{c}270.5 \\
(+8.0 \%)\end{array}$ & $\begin{array}{c}286.1 \\
(+14.2 \%)\end{array}$ & $\begin{array}{c}264.1 \\
(+5.4 \%)\end{array}$ \\
\hline
\end{tabular}

probably because the vertical concrete beam support displacements are very small in the first mode shape configuration. The natural frequencies obtained from the results of the dynamic analysis no. 6 , for the vibration modes no. 2 to 6 , were closer to the ones that can be identified in the ANPSD chart peaks (Fig. 8). The obtained frequency errors varied between $-1.4 \%$ and $+20.1 \%$ (Table 3 ).

Dynamic analysis no. 7 results presented a similar vibration mode shape configuration as for the previous analysis. However, they presented lower minimum $(+0.5 \%)$ and maximum $(+18.1 \%)$ error values, and they did not correspond to the same vibration mode numbers (Table 3 ).

\section{- FCEM steel frame solutions}

The results of the dynamic analysis no. 8 presented the lowest mean error values (Table 3 and Fig. 12). The maximum obtained error was $-13.3 \%$. It was noticed that vibration mode shape no. 5 and 6 obtained with FCEM dynamic analysis no. 8 were switched between each other, when compared with the FEM solutions.

\section{3. $\mathrm{RC}$ frame with infill walls results}

The last set of analysis allowed the determination of the dynamic response of a RC frame structure with non-structural infill masonry walls. Results are presented in Table 4 for the first three vibration modes.

\section{- FEM RC frame solutions}

Results of dynamic analysis no. 9 were obtained with FEM, without including masonry infill walls in the model (Fig. 7 - model no. 9). Only two vibration modes were obtained, with mode shapes only presenting horizontal displacements, because the mass was concentrated in the nodes resulting of the interceptions between beam and column elements (the typical modulation adopted for structural design). 

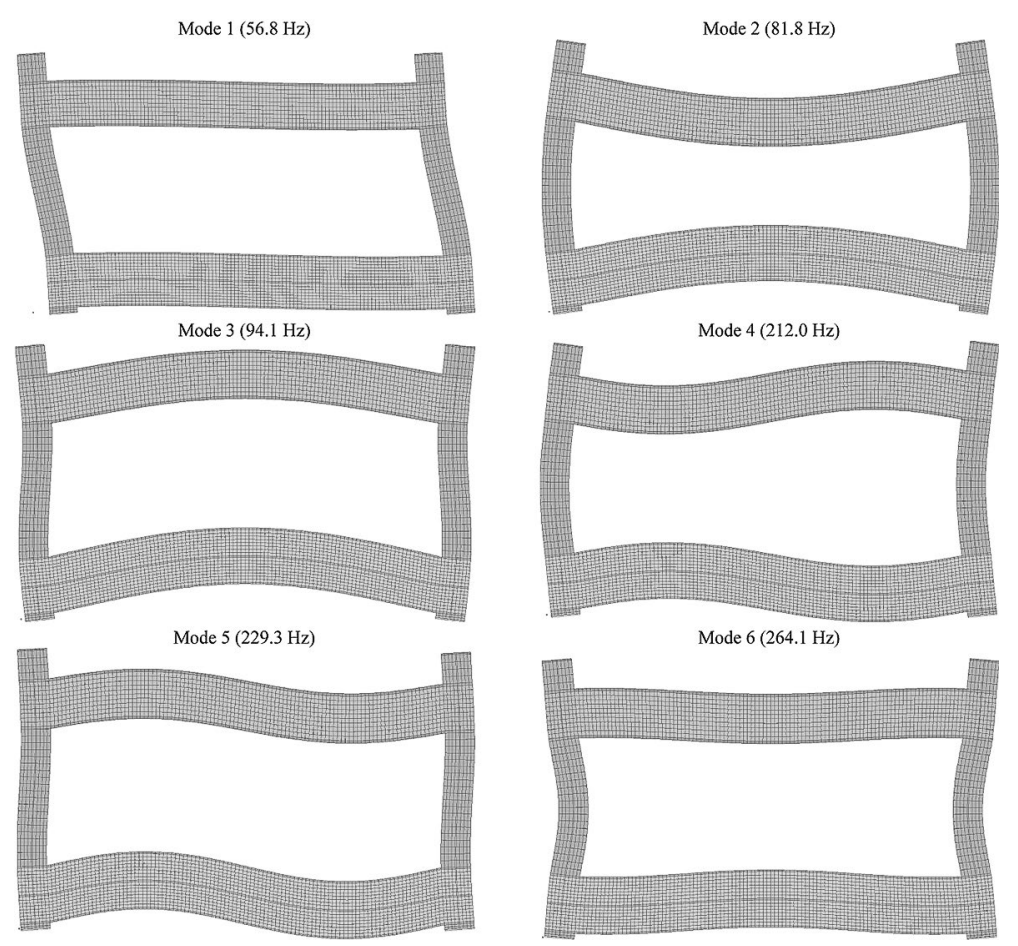

Fig. 12. Natural frequencies and vibration shape mode results of the analysis no. 8 (FCEM), for the first six frame vibration modes

Table 4. Natural frequency values $(\mathrm{Hz})$ obtained with different methods for the studied RC frame structure with infill masonry walls problem

\begin{tabular}{|c|c|c|c|c|c|}
\hline $\begin{array}{c}\text { Vibration } \\
\text { mode number }\end{array}$ & $\begin{array}{c}\text { Analysis no. 9 } \\
\text { (FEM) }\end{array}$ & $\begin{array}{c}\text { Vibration } \\
\text { mode number }\end{array}$ & $\begin{array}{c}\text { Analysis no. 10 } \\
\text { (FCEM) }\end{array}$ & $\begin{array}{c}\text { Vibration } \\
\text { mode number }\end{array}$ & $\begin{array}{c}\text { Analysis no. 11 } \\
\text { (FCEM) }\end{array}$ \\
\hline 1 & 1.7 & 1 & 3.8 & 1 & 1.7 \\
\hline 2 & 5.7 & 3 & 18.8 & 2 & 6.0 \\
\hline--- & --- & 2 & 15.3 & 3 & 9.3 \\
\hline
\end{tabular}

\section{- FCEM RC frame solutions}

Results obtained for analysis no. 10 (Fig. 13) with FCEM are rather different when compared to the results of analysis no. 9. The vibration modes no. 1 and 3 exhibit a similar shape as obtained for analysis no. 9 , but with higher frequencies $(+130.1 \%$ for mode 1 and $+228.9 \%$ for mode 3 ). The second vibration mode presented a different mode shape, with vertical displacements (Fig. 13), which is a consequence of the almost continuous distribution of the mass that was considered in the analysis no. 10 carried out with FCEM (Fig. 7 - model no. 10).

The shape of modes 1 and 2 of analysis no. 11 (FCEM) are similar to the obtained in analysis no. 9 (FEM), carried out with without including the masonry infill walls in the structural model $(+0.6 \%$ for mode 1 and $+5.3 \%$ for mode 2 ). The differences are probably related to the fact that in the FCEM model the columns deformable length are the real ones (which imply a stiffer structure) in spite of the nodes' deformation considered in FCEM analysis, which it is not the case for the FEM model adopted in analysis no. 9. Results obtained in analysis no. 11 also presented a third vibration mode with a shape similar to the results obtained in mode 2 of analysis no. 10 (Fig. 13), which was also carried out with FCEM. However, it presents a lower frequency which can be related to the absence of the infill masonry walls stiffness.

\section{Conclusions}

In this study a comparison between different solutions of dynamic continuous problems was carried out (between natural frequencies and vibration mode shapes), for a simply supported concrete beam, for a steel frame structure and for a reinforced concrete structure with masonry infill walls. The results of the experimental tests and of analytical expressions were compared with different numerical method results, namely the results 

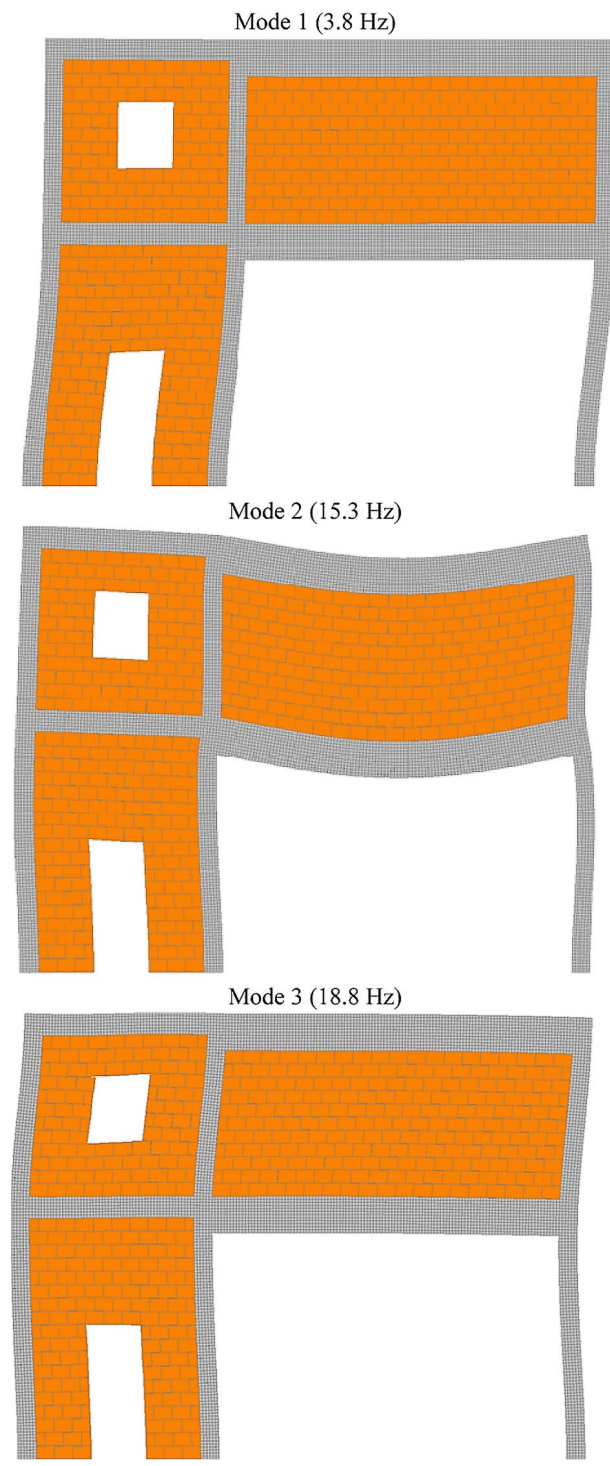

Fig. 13. Natural frequencies and vibration shape mode results of the analysis no. 10 (FCEM with infill walls), for the first vibration modes

obtained with Finite Element Method (FEM) and with the new Fibre Contact Element Method (FCEM).

The experimental test procedure was very helpful to validate FCEM. Using the experimental test results as a baseline, and the comparison between FEM and CFEM results, the major conclusions of this study for the RC beam structure and for the steel frame structure are:

- FCEM was the method that provided the solutions with lower mean error values for the studied RC beam and for the steel frame structure, when compared with the experimental test results, and seems that the obtained error depended on the structure discretization, and how supports are included in the model. FCEM errors were lower than FEM errors, even when FCEM used a lesser number of degrees-of-freedom for the global stiffness matrix.

- It was noticed that FCEM solutions are in general more flexible than FEM solutions, for the same structural conditions.

- The comparison of the results obtained in this study seems to indicate that discrete methods (normally developed for nonlinear analysis), like the new FCEM, can also be a valid option for solving real structural dynamic problems in the elastic domain.

The analysis carried out for the RC frame structure with infill masonry walls lead to the following major conclusions:

- The analyses carried out with FEM and considering the mass concentrated only in the nodes that link the beam and the column elements does not capture the correct structural dynamic behaviour, namely for the vertical direction.

- RC frame infill masonry walls dynamic analysis results obtained with FCEM show a change on the obtained frequency values when considering an almost continuous mass distribution and when considering the influence of the infill walls, which can be an important issue for seismic design, for example.

\section{References}

André, D.; Iordanoff, I.; Charles, J.-L.; Néauport, J. 2012. Discrete element method to simulate continuous material by using the cohesive beam model, Computer Methods in Applied Mechanics and Engineering 213-216: 113-125. http://dx.doi.org/10.1016/j.cma.2011.12.002

Azevedo, N. M.; Lemos, J. V. 2006. Hybrid discrete element/ finite element method for fracture analysis, Computer Methods in Applied Mechanics and Engineering 195(33-36): 45794593. http://dx.doi.org/10.1016/j.cma.2005.10.005

Bendat, J. S.; Piersol, A. G. 1993. Engineering applications of correlation and spectral analysis. John Wiley \& Sons.

Bendat, J. S.; Piersol, A. G. 2010. Random data: analysis and measurement procedures. John Wiley \& Sons, Inc. http://dx.doi.org/10.1002/9781118032428

Braga, A. M. G. S.; Estêvão, J. M. C. 2007. Estudo da viabilidade da construção em alvenaria confinada no Algarve [Study of the feasibility of confined masonry construction in Algarve] (in Portuguese), in $7^{\circ}$ Congresso de Sismologia e Engenharia Sísmica, 26-28 September 2007 Porto. FEUP, CD 063, 14 p.

Caliò, I.; Marletta, M.; Pantò, B. 2012. A new discrete element model for the evaluation of the seismic behaviour of unreinforced masonry buildings, Engineering Structures 40: 327-338. http://dx.doi.org/10.1016/j.engstruct.2012.02.039 
Carmona, H. A.; Wittel, F. K.; Kun, F. 2014. From fracture to fragmentation: Discrete element modeling, The European Physical Journal Special Topics 223(11): 2369-2382. http://dx.doi.org/10.1140/epjst/e2014-02270-3

Casolo, S.; Milani, G. 2010. A simplified homogenizationdiscrete element model for the non-linear static analysis of masonry walls out-of-plane loaded, Engineering Structures 32(8): 2352-2366.

http://dx.doi.org/10.1016/j.engstruct.2010.04.010

Clough, R. W.; Penzien, J. 1993. Dynamics of structures. Singapore: McGraw-Hill.

CSI. 2014. SAP2000 version 16.10 Ultimate - Integrated Software for Structural Analysis \& Design. Berkeley: Computers \& Structures, Inc.

D'addetta, G. A.; Kun, F.; Ramm, E. 2002. On the application of a discrete model to the fracture process of cohesive granular materials, Granular Matter 4(2): 77-90. http://dx.doi.org/10.1007/s10035-002-0103-9

Dimitri, R.; De Lorenzis, L.; Zavarise, G. 2011. Numerical study on the dynamic behavior of masonry columns and arches on buttresses with the discrete element method, Engineering Structures 33(12): 3172-3188.

http://dx.doi.org/10.1016/j.engstruct.2011.08.018

Estêvão, J. M. C. 2012. Efeitos da ação sísmica no comportamento de edifícios de betão armado com alvenarias de enchimento [Seismic effects on the behavior of reinforced concrete buildings with infill walls] (in Portuguese): PhD Thesis. Instituto Superior Técnico, UTL, Lisboa, Portugal.

Estêvão, J. M. C.; Carvalho, A. 2015. The role of source and site effects on structural failures due to Azores earthquakes, Engineering Failure Analysis 56: 429-440. http://dx.doi.org/10.1016/j.engfailanal.2014.12.010

Estêvão, J. M. C.; Oliveira, C. S. 2015. A new analysis method for structural failure evaluation, Engineering Failure Analysis 56: 573-584. http://dx.doi.org/10.1016/j.engfailanal.2014.08.009

Felber, A. J. 1993. Development of a hybrid bridge evaluation system: PhD Dissertation. University of British Columbia, Vancouver, Canada.

Grima, A.; Wypych, P. 2011. Development and validation of calibration methods for discrete element modelling, Granular Matter 13(2): 127-132.

http://dx.doi.org/10.1007/s10035-010-0197-4

Huang, Y. J.; Nydal, O. J.; Ge, C.; Yao, B. 2015. An introduction to discrete element method: a meso-scale mechanism analysis of granular flow, Journal of Dispersion Science and Technology 36(10): 1370-1377.

http://dx.doi.org/10.1080/01932691.2014.984304

Jebahi, M.; Dau, F.; Charles, J.-L.; Iordanoff, I. 2014. Multiscale modeling of complex dynamic problems: an overview and recent developments, Archives of Computational Methods in Engineering: 1-38.

http://dx.doi.org/10.1007/s11831-014-9136-6

Jin, F.; Zhang, C.; Hu, W.; Wang, J. 2011. 3D mode discrete element method: elastic model, International Journal of Rock Mechanics and Mining Sciences 48(1): 59-66. http://dx.doi.org/10.1016/j.ijrmms.2010.11.003

Lemos, J. V. 2007. Discrete element modeling of masonry structures, International Journal of Architectural Heritage 1(2): 190-213. http://dx.doi.org/10.1080/15583050601176868
Liu, K.; Liu, W. 2006. Application of discrete element method for continuum dynamic problems, Archive of Applied Mechanics 76(3-4): 229-243. http://dx.doi.org/10.1007/s00419-006-0018-8

McInerney, J.; DeJong, M. J. 2014. Discrete element modelling of groin vault displacement capacity, International Journal of Architectural Heritage.

http://dx.doi.org/10.1080/15583058.2014.923953

Mechtcherine, V.; Gram, A.; Krenzer, K.; Schwabe, J.-H.; Bellmann, C.; Shyshko, S. 2014. Simulation of fresh concrete flow using discrete element method (DEM), in N. Roussel, A. Gram (Eds.). Simulation of fresh concrete flow. Netherlands: Springer.

http://dx.doi.org/10.1007/978-94-017-8884-7_3

Meguro, K.; Tagel-Din, H. 2001. Applied element simulation of RC structures under cyclic loading, Journal of Structural Engineering 127(11): 1295-1305.

http://dx.doi.org/10.1061/(ASCE)0733-9445(2001)127:11(1295)

Milani, G.; Casolo, S.; Naliato, A.; Tralli, A. 2011. Seismic assessment of a medieval masonry tower in Northern Italy by limit, nonlinear static, and full dynamic analyses, International Journal of Architectural Heritage 6(5): 489-524. http://dx.doi.org/10.1080/15583058.2011.588987

Ndambi, J. M.; Giannopoulos, G.; Vantomme, J. 2005. Dynamic characterisation of an IPC pedestrian bridge, Engineering Structures 27(2): 229-237.

http://dx.doi.org/10.1016/j.engstruct.2004.09.010

Norouzi, S.; Baghbanan, A.; Khani, A. 2013. Investigation of grain size effects on micro/macro-mechanical properties of intact rock using Voronoi element-discrete element method approach, Particulate Science and Technology 31(5): 507-514. http://dx.doi.org/10.1080/02726351.2013.782929

Paeglite, I.; Paeglitis, A.; Smirnovs, J. 2015. Dynamic amplification factor for bridges with span length from 10 to 35 meters, Engineering Structures and Technologies 6(4): 151-158. http://dx.doi.org/10.3846/2029882x.2014.996254

Rafiee, A.; Vinches, M. 2013. Mechanical behaviour of a stone masonry bridge assessed using an implicit discrete element method, Engineering Structures 48: 739-749.

http://dx.doi.org/10.1016/j.engstruct.2012.11.035

Schlangen, E.; Garboczi, E. J. 1996. New method for simulating fracture using an elastically uniform random geometry lattice, International Journal of Engineering Science 34(10): 1131-1144. http://dx.doi.org/10.1016/0020-7225(96)00019-5

Schlangen, E.; Garboczi, E. J. 1997. Fracture simulations of concrete using lattice models: Computational aspects, Engineering Fracture Mechanics 57(2-3): 319-332. http://dx.doi.org/10.1016/S0013-7944(97)00010-6

Seyedi Hosseininia, E. 2012. Investigating the micromechanical evolutions within inherently anisotropic granular materials using discrete element method, Granular Matter 14(4): 483-503. http://dx.doi.org/10.1007/s10035-012-0340-5

Shannon, C. E. 1949a. Communication in the presence of noise, Proceedings of the IRE: Journal of Communications and Electronic Engineering 37(1): 10-21.

Shannon, C. E. 1949b. Communication theory of secrecy systems, Bell System Technical Journal 28(4): 656-715. http://dx.doi.org/10.1002/j.1538-7305.1949.tb00928.x 
Smoljanović, H.; Živaljić, N.; Nikolić, Ž. 2013. A combined finite-discrete element analysis of dry stone masonry structures, Engineering Structures 52: 89-100. http://dx.doi.org/10.1016/j.engstruct.2013.02.010

Tatone, B. S. A.; Grasselli, G. 2015. A calibration procedure for two-dimensional laboratory-scale hybrid finite-discrete element simulations, International Journal of Rock Mechanics and Mining Sciences 75: 56-72.

http://dx.doi.org/10.1016/j.ijrmms.2015.01.011
Ulrich, T.; Negulescu, C.; Ducellier, A. 2015. Using the discrete element method to assess the seismic vulnerability of aggregated masonry buildings, Bulletin of Earthquake Engineering: 1-16. http://dx.doi.org/10.1007/s10518-015-9754-x

$\mathrm{Wu}, \mathrm{M}$; Z Zhang, C. 2015. Influence of static pre-loading on the dynamic bending strength of concrete with particle element modeling, Science China Technological Sciences 58(2): 284296. http://dx.doi.org/10.1007/s11431-014-5671-5

João M. C. ESTÊVÃO. PhD in Civil Engineering (Earthquake engineering) and MSc in Structural Engineering. Presently, he is a Professor at the Department of Civil Engineering of the University of Algarve, Portugal. Main research interests: seismic hazard analysis, dynamic analysis of layered soils, structural dynamic analysis (masonry buildings and reinforced concrete buildings), seismic risk assessment.

Ana S. CARREIRA. PhD student in Civil Engineering and MSc in Structural Engineering. Currently, she works at the Department of Civil Engineering of the University of Algarve, Portugal. Main research interests: structural acoustics and vibration, structural modal identification. 